\title{
Updating of Finite Element Models Including Damping
}

$$
\text { 감쇠를 포함한 유한요소 모형의 개선 }
$$

\author{
Gun-Myung Lee ${ }^{\dagger}$, Young-Ho Ju* and Mun-Soo Park** \\ 이 건 명.주 영 호.박 문 수
}

(Received September 25, 2012 ; Revised October 29, 2012 ; Accepted October 29, 2012)

Key Words : Model Updating(모형개선), Finite Element Analysis(유한요소해석), Damping(감쇠), Optimization(최적 화), Proportional Damping(비례감쇠)

\begin{abstract}
Finite element models are updated in two stages in this paper. In the first stage, damping is neglected, and mass and stiffness matrices of a finite element model are updated using an optimization technique. The objective function for optimization consists of natural frequencies and mode shapes obtained from experimental modal testing data and finite element analysis. In the second stage, damping is considered with the mass and stiffness matrices fixed. A damping matrix is estimated assuming a proportional damping system. Then the damping matrix is adjusted using an optimization process so that the difference between the analytical and measured frequency response functions becomes minimum. This procedure of model updating has been applied to a simulated system and an experimental cantilever beam.
\end{abstract}

\section{요 약}

이 논문에서 유한요소 모형은 2 단계로 개선된다. 첫 단계에서는 감쇠를 무시하고, 최적화 방법을 사용 하여 유한요소 모형의 질량행렬과 강성행렬을 개선한다. 최적화를 위한 목적함수는 모드시험 데이터와 유 한요소해석으로부터 구한 고유진동수와 진동형으로 이루어져 있다. 두 번째 단계에서는 첫 단계에서 구한 질량행렬과 강성행렬을 고정시키고, 감쇠를 고려한다. 먼저 비례감쇠를 가정하고 감쇠행렬을 추정한 다음, 해석적인 주파수응답함수와 측정한 주파수응답함수의 차가 최소가 되도록 최적화 과정을 이용하여 감쇠행 렬을 조정한다. 이와 같은 모형개선 방법을 시뮬레이션 계와 실제 외팔보에 적용하였다.

\section{Introduction}

It has become necessary to predict the responses of complicated mechanical systems and structures under dynamic loadings. Since the responses can be hardly predicted analytically, numerical methods are usually employed for that purpose, and finite element analysis(FEA) is one of the methods used frequently. Numerical pre-

† Corresponding Author; Member, Engineering Research Institute, Gyeongsang National University

E-mail : gmlee@gnu.ac.kr

Tel : +82-55-772-1621, Fax : +82-55-772-1577

* Doosan Heavy Industries and Construction

** Jinju Campus, Korea Polytechnic VII College

\# Recommended by Editor Don Chool Lee

(c) The Korean Society for Noise and Vibration Engineering 
dictions of the behaviour of a physical system is limited by the assumptions used in the development of the mathematical model. As a result, the predicted responses may differ from the experimentally measured ones.

In those cases, finite element models can be updated so that the predicted responses based on the models agree with the measured ones. Finite element model updating has emerged in the 1990s as a subject of immense importance to the design, construction and maintenance of mechanical systems and civil engineering structures. The related researches are surveyed ${ }^{(1)}$ and summarized $^{(2)}$ in references. The approaches to model updating include the sensitivity analysis ${ }^{(3)}$ and the frequency response function(FRF) method developed by $\operatorname{Lin}^{(4)}$ and Imregun ${ }^{(5)}$. Brief description on those approaches is omitted here because it is included in the previous papers ${ }^{(6,7)}$ by the authors. Usually damping is not considered in finite element model updating, and the stiffness and mass matrices of the systems under consideration are updated. Model updating including damping has been performed in few researches ${ }^{(8 \sim 10)}$.

The authors proposed finite element model updating in two stages ${ }^{(6,7)}$. In the first stage, damping is neglected, and mass and stiffness matrices of a finite element model are updated using an optimization technique. The objective function for optimization consists of natural frequencies and mode shapes obtained from experimental modal testing data and FEA. In the second stage, damping is considered with the mass and stiffness matrices fixed. To consider damping three methods were applied ${ }^{(7)}$. Method 1 estimates a damping matrix from the modal matrix and the modal parameters. The modal matrix is obtained from the finite element model updated in the first stage, and the modal parameters are extracted from the measured FRFs. Since the method assumes proportional damping, its application is limited to proportional damping systems. Method 2 estimates a damping matrix from the imaginary part of the impedance matrix which is the inverse of the FRF matrix $^{(11)}$. One drawback of the method is that it requires the inverse of a full FRF matrix. Measurement of a full FRF matrix takes a long time and much effort especially when the degree of freedom is large. Another one is that small errors in a FRF matrix may result in large errors after calculating its inverse. Application of this method to simulated data showed that the estimated damping matrix was very sensitive to added noise. From these results it may be concluded that method 2 is not suitable for estimating a damping matrix unless very accurate FRFs without noise are measured. Method 3 calculates correction to the initial damping matrix from the difference between the analytical and measured FRFs. The method requires measurement of one column of a FRF matrix. When using the method, FRFs corresponding to rotational degrees of freedom are needed. Since these FRFs are not usually measured during modal testing, they can be either approximated from their corresponding analytical FRFs or calculated from measured FRFs for translational degrees of freedom. Conclusively the above methods to estimate a damping matrix have a limitation in their application or cannot estimate accurate damping matrices.

A new method is proposed in this paper to estimate an accurate damping matrix in the second stage of finite element model updating. The method is applicable to non-proportional damping systems as well as proportional damping systems. To investigate the effectiveness and limitations of the method, it is applied to a simulated 4 dof system and a cantilever beam.

\section{Finite Element Model Updating}

\subsection{First Stage}

In the first stage of model updating, finite element models are updated using an optimization 
technique. The objective function for optimization consists of the differences between the analytical responses from FEA and the measured responses. The chosen response parameters are natural frequencies and mode shapes. To represent the differences between mode shapes, MAC(modal assurance criterion) values are used. The objective function can be composed as Eq. (1).

$$
F_{o}=\sum_{i=1}^{n}\left(\frac{\omega_{a i}-\omega_{m i}}{\omega_{m i}}\right)^{2}+\sum_{i=1}^{n}\left(1-M A C_{i}\right)
$$

In the above equation $\omega$ indicates a natural frequency, the subscripts ' $a$ ', ' $m$ ', and ' $i$ ' imply 'analytical', 'measured', and mode number, respectively, and $n$ represents the number of modes considered.

As updating variables of a finite element model which affect the objective function in Eq. (1), material properties such as Young's modulus, physical dimensions such as thickness, boundary conditions, and parameters of attached sensors which cause a loading error can be selected.

\subsection{Second Stage}

In the second stage of model updating, damping is considered with the mass and stiffness matrices fixed. Damping estimation starts from the damping estimation of a proportional damping system. For systems with proportional damping, the following relation holds.

$$
[X]^{T}[C][X]=\left[C_{i i}\right]
$$

where $[X]$ is the modal matrix whose columns represent the mode shapes, and $\left[C_{i i}\right]$ is a diagonal matrix whose $i$-th element has the value of $2 \zeta_{i} \omega_{i}$ where $\zeta_{i}$ and $\omega_{i}$ represent the damping ratio and the natural frequency of mode $i$, respectively. These modal parameters can be estimated from the measured FRFs using a modal parameter extraction algorithm, for example, the complex exponential algorithm ${ }^{(12)}$. The diagonal elements of
$\left[C_{i i}\right]$ corresponding to the modes outside the analysis frequency range are set to zeros. From the above relation the matrix $[C]$ can be obtained as follows.

$$
[C]=\left([X][X]^{T}\right)^{-1}[X]\left[C_{i i}\right][X]^{T}\left([X][X]^{T}\right)^{-1}
$$

The above equation means that the damping matrix can be obtained from the estimated natural frequencies and damping ratios, and the modal matrix. On the assumption that the mode shapes of a lightly damped system are similar to the mode shapes of the corresponding undamped system, the modal matrix $[X]$ obtained from the updated finite element model in the first stage can be used in the above equation. The FRFs of the system can be predicted using the above damping matrix and Eq. (4).

$$
[H]=\left([K]-\omega^{2}[M]+i \omega[C]\right)^{-1}
$$

where $[M]$ and $[K]$ represent the mass and stiffness matrices obtained in the first stage. If the measured and predicted FRFs agree well, it is concluded that the considered system exhibits proportional damping characteristics, and the model updating procedure stops.

For a non-proportional damping system, the damping matrix obtained by Eq. (3) is not valid and it should be adjusted further. Taking the above damping matrix as a starting point, an optimization process can be performed to minimize the sum of the differences between analytical and measured FRFs. When performing an optimization process, part of the elements of a damping matrix which have large sensitivities may be selected as updating variables.

\section{Application of the Model Updating Procedure}

The proposed two stage model updating procedure was applied to a simulated 4 dof system and 
a simple steel cantilever beam. Since the first stage of the procedure is described in the authors' previous research ${ }^{(6,7)}$, this paper focuses on the damping estimation in the second stage.

\subsection{A Simulated 4 dof System}

To demonstrate the effectiveness of the procedure, a 4 dof simulated system in Fig. 1 was considered. The system parameters are $m_{1}=m_{2}=m_{3}$ $=m_{4}=1 \mathrm{~kg}, \quad k_{1}=k_{2}=k_{3}=k_{4}=1000 \mathrm{~N} / \mathrm{m}, \quad c_{1}=c_{2}=5 \mathrm{Ns} / \mathrm{m}$ and $c_{3}=c_{4}=10 \mathrm{Ns} / \mathrm{m}$, resulting in non-proportional damping. It is assumed that accurate mass and stiffness matrices of the system are obtained in the first stage. Modal parameters of the system are extracted from the analytical FRFs calculated using Eq. (4). Assuming proportional damping, a damping matrix is calculated using Eq. (3). The exact damping matrix of the system and the matrix estimated assuming proportional damping are given in Eqs. (5) and (6), respectively.

$$
\begin{aligned}
{[C] } & =\left[\begin{array}{cccc}
10 & -5 & 0 & 0 \\
-5 & 15 & -10 & 0 \\
0 & -10 & 20 & -10 \\
0 & 0 & -10 & 10
\end{array}\right] \\
{[C]_{e} } & =\left[\begin{array}{cccc}
15.567 & -7.801 & 0.585 & -0.570 \\
-7.801 & 16.151 & -8.371 & 0.015 \\
0.585 & -8.371 & 15.582 & -7.786 \\
-0.570 & 0.015 & -7.786 & 7.780
\end{array}\right]
\end{aligned}
$$

The difference between two matrices is not small. The estimation error defined in Eq. (7) becomes $27.60 \%$.

$$
\text { error }=\frac{\sum\left|\Delta e_{i j}\right|}{\sum\left|e_{i j}\right|} \times 100
$$

In the above equation, $e_{i j}$ and $\Delta e_{i j}$ represent each element of a matrix and its error, respectively. Fig. 2 compares the exact FRF and the predicted FRF using the damping matrix in Eq. (6).
To adjust the estimated damping matrix, an optimization process was performed. The objective function was formed as a sum of the differences between the exact and predicted FRFs. When calculating the predicted FRFs using Eq. (4), it was assumed that the exact mass and stiffness matrices of the system were obtained in the first stage. All the upper triangular elements, that is, 10 elements of the $4 \times 4$ damping matrix were selected as updating variables. The matrix in Eq. (6) served as the starting point of an optimization process. The updating variables were constrained to vary between 0 and two times the initial values. Using a constrained optimizer function of MATLAB ${ }^{(13)}$, an optimum point was arrived. At the reached optimum point, the estimated damping matrix became

$$
[C]_{e}=\left[\begin{array}{cccc}
11.415 & -4.575 & 0.258 & -0.969 \\
-4.575 & 14.214 & -9.639 & 0.030 \\
0.258 & -9.639 & 19.941 & -10.269 \\
-0.969 & 0.030 & -10.269 & 10.551
\end{array}\right]
$$

Comparing the matrix with that in Eq. (6), the accuracy of the estimated damping matrix has

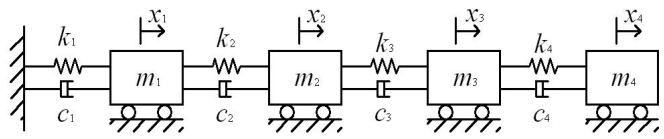

Fig. 1 A 4 dof system with lumped parameters

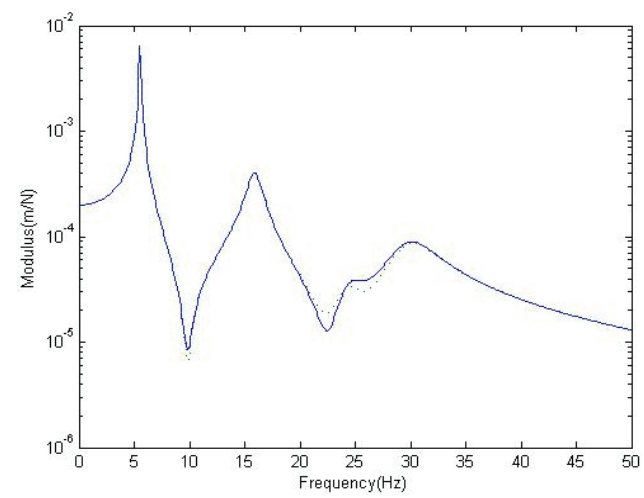

Fig. 2 Comparison of the exact(solid line) and predicted(dotted line) FRFs for the 4 dof system 
been much improved. The estimation error defined by Eq. (7) becomes $7.08 \%$ in this case. When the FRFs were calculated using this damping matrix, the predicted FRFs agreed with the exact ones almost exactly. Hence those FRFs are not shown for brevity.

A genetic algorithm was applied to the above optimization problem. The same objective function, updating variables, and bounds for the variables were used. When the values of the used population size, the number of maximum generation, the crossover probability, and the mutation probability were equal to $120,3000,0.9,0.1$, respectively, an optimum point closer to the exact one was reached. The obtained damping matrix is given in Eq. (9).

$$
[C]_{e}=\left[\begin{array}{cccc}
10.307 & -5.008 & 0.176 & -0.057 \\
-5.008 & 14.748 & -9.958 & 0.018 \\
0.176 & -9.958 & 20.006 & -10.055 \\
-0.057 & 0.018 & -10.055 & 10.026
\end{array}\right]
$$

The obtained damping matrix in Eq. (9) is very close to the exact one in Eq. (5) and the corresponding estimation error is $1.24 \%$ only. However, one disadvantage of a genetic algorithm is that it requires a much longer computation time than gradient based algorithms.

\subsection{A Cantilever Beam}

The proposed two stage model updating procedure was applied to a simple steel cantilever beam with length $0.27 \mathrm{~m}$, width $0.034 \mathrm{~m}$, thickness $0.0015 \mathrm{~m}$, and density $7850 \mathrm{~kg} / \mathrm{m}^{3}$. For FEA, the beam is divided into five elements with equal length. Hence the finite element model of the beam has 5 nodes and 10 dofs. FEA and modal testing of the beam are described in detail in the authors' previous paper ${ }^{(6)}$. Performing the first stage of the proposed model updating procedure, the positions of resonant peaks agree very well between the measured and predicted FRFs, but the moduli of peaks differ due to neglect of damping as shown in Fig. 3.

Assuming proportional damping, a damping matrix was obtained using Eq. (3). In this equation, the modal matrix $[\mathrm{X}]$ was obtained from the updated finite element model in the first stage, and $\left[C_{i i}\right]$ from the estimated modal parameters. With the obtained damping matrix, the FRFs were calculated using Eq. (4), and one of them is compared with its corresponding measured one in Fig. 4. Examining the figure, one can observe that the analytical FRF agrees well with the measured one except near zero frequency, indicating that the updated finite element model is reasonably accurate.

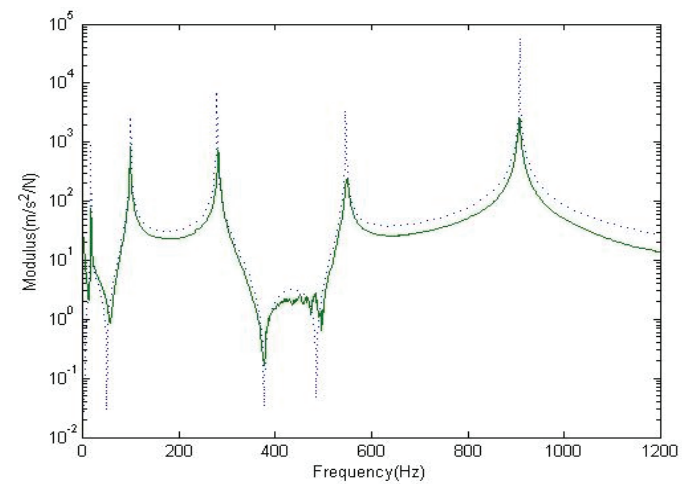

Fig. 3 Comparison of the measured(solid line) and predicted(dotted line) FRFs after the first stage

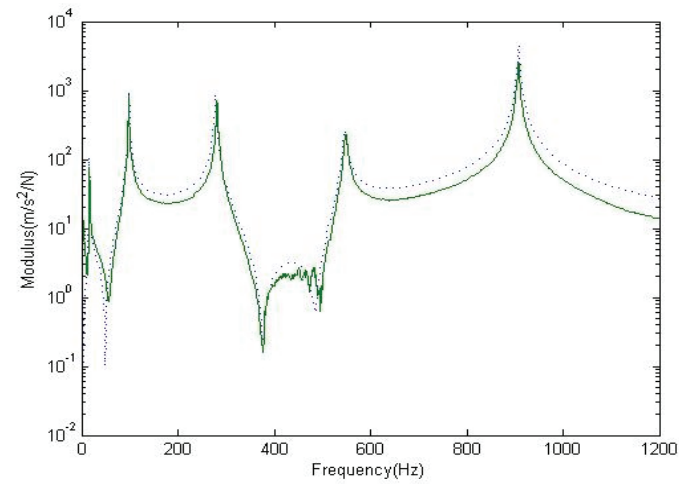

Fig. 4 Comparison of the measured(solid line) and predicted(dotted line) FRFs after proportional damping is considered 


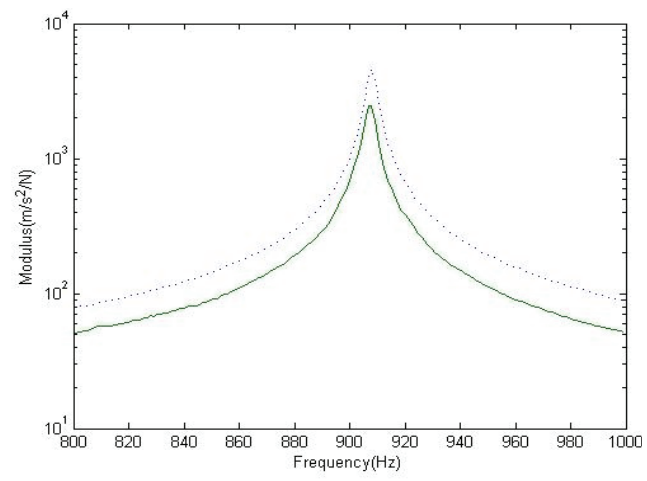

Fig. 5 Comparison of the measured(solid line) and predicted(dotted line) FRFs before the damping matrix adjustment

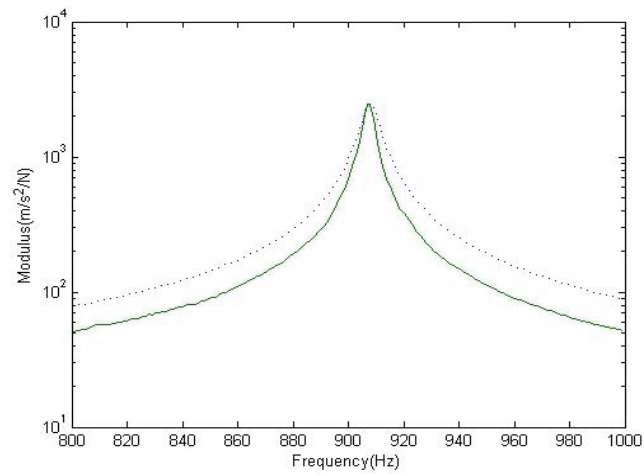

Fig. 6 Comparison of the measured(solid line) and predicted(dotted line) FRFs after the damping matrix adjustment

Disagreement between two FRFs near zero frequency is due to inherent characteristics of piezoelectric transducers.

Next, the above damping matrix was adjusted through an optimization process. Since the degree of freedom of the beam is 10 , the damping matrix is a $10 \times 10$ matrix and is composed of 55 different elements considering the symmetry of the matrix. If one selects all these elements as updating variables, there are too many updating variables, resulting in a time-consuming optimization process. To reduce the number of updating variables, the sensitivities of FRFs to the change of an element of the damping matrix were calculated around resonance frequencies. It is because FRFs are sensitive to the change of a damping matrix around resonance frequencies. Those elements with large sensitivities were selected as updating variables, and they are $C_{17}, C_{33}, C_{37}, C_{39}, C_{47}, C_{55}, C_{57}, C_{67}$, $C_{77}, C_{79}$, and $C_{99}$. These updating variables were constrained to vary between 0 and two times their initial values. Without constraints for elements of system matrices, matrices which do not have physical meanings may be resulted through optimization processes. The objective function was formed as a sum of the differences between the measured and analytical FRFs. Using a constrained optimizer function of MATLAB, an optimum point was arrived and the objective function was reduced by $16.7 \%$. When FRFs were calculated with the updated damping matrix using Eq. (4) and compared with the measured ones, the agreement at resonance peaks improved. Figs. 5 and 6 compare the measured and predicted FRFs around the fifth mode at $908 \mathrm{~Hz}$ before and after the adjustment of the damping matrix, respectively. One can observe that resonance peaks agree exactly after the adjustment. These results imply that an accurate damping matrix has been estimated through the model updating procedure.

\section{Conclusions}

A procedure to update finite element models is proposed and applied to a simulated 4 dof system and a steel cantilever beam. The updating procedure is composed of two stages. In the first stage, damping is neglected, and the mass and stiffness matrices of a finite element model are updated using an optimization technique.

In the second stage, damping is considered with the mass and stiffness matrices fixed. First, a damping matrix is estimated assuming a proportional damping system. Then the damping matrix is adjusted using an optimization process so that the difference between the analytical and measured FRFs becomes minimum. Applications to a simu- 
lated and an experimental system showed that this procedure can estimate accurate damping matrices. When a genetic algorithm is used for an optimization process, more accurate results can be obtained with the expense of a long computation time.

\section{Acknowledgments}

This work was supported by the second stage BK21 project.

\section{References}

(1) Mottershead, J. E. and Friswell, M. I., 1993, Model Updating in Structural Dynamics : A Survey, Journal of Sound and Vibration, Vol. 167, No. 2, pp. 347 375.

(2) Friswell, M. I. and Mottershead, J. E., 1995, Finite Element Model Updating in Structural Dynamics, Kluwer Academic Publishers.

(3) Jeong, W. B., Yoo, W. S. and Kim, J. Y., 2003, Sensitivity Analysis of Anti-resonance Frequency for Vibration Test Control of a Fixture, KSME International Journal, Vol. 17, No. 11, pp. 1732 1738.

(4) Lin, R. M. and Ewins, D. J., 1994, Analytical Model Improvement Using Frequency Response Functions, Mechanical Systems and Signal Processing, Vol. 8, No. 4, pp. 437 458.

(5) Imregun, M., Visser, W. J. and Ewins, D. J., 1995, Finite Element Model Updating Using Rrequency Response Function Data - I. Theory and Initial Investigation, Mechanical Systems and Signal Processing, Vol. 9, No. 2, pp. 187 202.

(6) Lee, G.-M., Kim, K.-J. and Ju, Y.-H., 2009, Estimation of Damping Matrices for Dynamic Systems, Transactions of the Korean Society for Noise and Vibration Engineering, Vol. 19, No. 10, pp. 1021 1027.

(7) Lee, G.-M., Ju, Y.-H. and Park, M.-S., 2010, Comparison of Damping Matrix Estimation Methods for Model Updating, Transactions of the Korean Society for Noise and Vibration Engineering, Vol. 20, No. 10, pp. 923 930.
(8) Lu, Y. and Tu, Z., 2004, A Two-level Neural Network Approach for Dynamic FE Model Updating Including Damping, Journal of Sound and Vibration, Vol. 275, No. 3-5, pp. 931 952.

(9) Lin, R. M. and Zhu, J., 2006, Model Updating of Damped Structures Using FRF Data, Mechanical Systems and Signal Processing, Vol. 20, No. 8, pp. 2200 2218.

(10) Minas, C. and Inman, D. J., 1988, Correcting Finite Element Models with Measured Modal Results Using Eigenstructure Assignment Methods, Proceedings of the 6th International Modal Analysis Conference, pp. $583 \sim 587$.

(11) Ozgen, G. O. and Kim, J. H., 2009, Error Analysis and Feasibility Study of Dynamic Stiffness Matrix-based Damping Matrix Identification, Journal of Sound and Vibration, Vol. 320, No. 1-2, pp. 60 83.

(12) Ewins, D. J., 1995, Modal Testing : Theory and Practice, Research Studies Press Ltd.

(13) User's Guide(Version 3), 2004, Optimization Toolbox For Use with MATLAB, The MathWorks, Inc., Natick, MA.

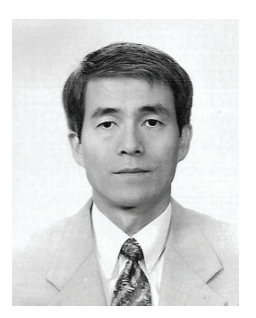

Gun-Myung Lee received his $\mathrm{Ph}$. D. degree from the Pennsylvania State University in 1988. He is currently a professor at the Gyeongsang National University. His research areas are modal testing, system identification, and model

updating.

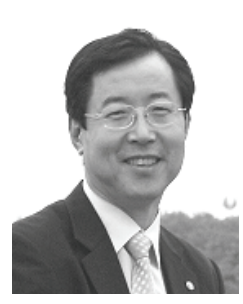

Mun-Soo Park received his master's degree in Mechanical Engineering from the Gyeongsang National University in 1997. He is currently a professor with Department of Computer Application Machine at Jinju Campus of Korea Polytechnic. He is also currently a doctoral student in the Department of Mechanical Engineering at the Gyeongsang National University. His research interests include modal testing and MR dampers. 